\title{
Microwave Field Effect on Polyphenolic Compounds from Aromatic Plants
}

\author{
Maria-Loredana Soran ${ }^{* 1}$, Manuela Stan', Ildiko Lung ${ }^{3}$, Mihail R. C. Truşcă \\ ${ }^{1}$ National Institute for Research and Development of Isotopic and Molecular Technologies, \\ 67-103 Donat Street, RO-400293, Cluj-Napoca, Romania \\ e-mail: loredana.soran@irim-cj.ro \\ ${ }^{2}$ National Institute for Research and Development of Isotopic and Molecular Technologies, \\ 67-103 Donat Street, RO-400293, Cluj-Napoca, Romania \\ e-mail: manuela.stan@itim-cj.ro \\ ${ }^{3}$ National Institute for Research and Development of Isotopic and Molecular Technologies, \\ 67-103 Donat Street, RO-400293, Cluj-Napoca, Romania \\ e-mail: ildiko.lung@itim-cj.ro \\ ${ }^{4}$ National Institute for Research and Development of Isotopic and Molecular Technologies, \\ 67-103 Donat Street, RO-400293, Cluj-Napoca, Romania \\ e-mail: radu.trusca@itim-cj.ro
}

Cite as: Soran, M.-L., Stan, M., Lung, I., Truşcă, M. R. C., Microwave Field Effect on Polyphenolic Compounds from Aromatic Plants, J. sustain. dev. energy water environ. syst., 4(1), pp 48-55, 2016, DOI: http://dx.doi.org/10.13044/j.sdewes.2016.04.0005

\begin{abstract}
Nowadays, the use of mobile telephony and wire-less devices has become more demanding, generating electromagnetic radiations. Microwave radiation can affect the growth rate of plants. For this study, the aromatic plants i.e. parsley, celery, dill, basil, were chosen as irradiated plants. This study aims to investigate the effects of irradiation with microwave field on polyphenolic compounds from basil, celery and parsley. The extracts were obtained by sonication. Quantitative analysis of polyphenolic compounds was performed by high performance liquid chromatography using an Altima C18 column. The elution was performed in gradient, with acetonitrile (eluent A) and formic acid in water (1\%, eluent B). It was observed that in the irradiated plants, the content of polyphenolic compounds was higher than in the controlled plant. This finding suggests that that plants were strongly influenced by stress due to electromagnetic fields.
\end{abstract}

\section{KEYWORDS}

Polyphenolic compounds, Aromatic plants, Microwave irradiation, High-Performance Liquid Chromatography - Diode Array Detection-Mass Spectrometry (HPLC-DAD-MS).

\section{INTRODUCTION}

The use of plant food sources especially food herbs in traditional medicine has increased the interest in exploring their beneficial effects on human health. Approximately $70 \%$ of global population utilize traditional medicine obtained from plants to treat and cure various ailments [1].

Polyphenolic compounds are secondary metabolites, which play an important role in growth and reproduction, providing protection against pathogens and predators, besides contributing towards the color and sensory characteristics of fruits and vegetables [2]. Studies on phenolic compounds have shown a wide range of biological activities such as anti-inflammatory, hepatoprotective, antioxidant, antitrombotic, vasodilating and anticarcinogenic [2].

* Corresponding author 
In recent years the role of phenolic compounds and flavonoids as protective dietary constituents has become an increasingly important area of human nutrition research.

The Lamiaceae and Apiaceae family plants are also a source of phenolic compounds with high biological activity. Many species of Lamiaceae family have been widely used in traditional medicine and as spices in food for centuries [2]. Among the aromatic plants belonging to Lamiaceae family, one that is frequently used is basil (Ocimum basilicum L.), native to India and cultivated in other regions of Asia, Africa and the Mediterranean region. Basil shows antioxidant and antimicrobial activities due to its phenolic and aromatic compounds [3].

Parsley (Petroselinum crispum) is a vegetable plant, cultivated for its white root and aromatic leaves used in food and folk medicine. Due to the complex composition, parsley has a number of medicinal properties [4-6], i.e. antimicrobial, anti-inflammatory, diuretic and depurative, antiseptic, etc.

Celery (Apium graveolens) that is frequently used in folk medicine has a number of curative properties [7, 8]. It is being used as a remedy for high blood pressure, detoxification of the body or basis for homeopathic extracts used in various diseases (gout, arthritis, fatigue, cough, etc.).

Plants and influence of the environmental stress conditions present a great importance lately as a field of study and research [9]. Among the various types of stress that affect plants growth are: temperature, drought, salinity, microwaves. Several studies have shown that basil increases its resistance property to stress conditions [10]. The water deficit revealed an increased amount of essential oil and resulted in the composition changes of Petroselinum crispum [11]. Similarly, high salinity resulted in increased of essential oil amount in Anthem graveolens plants grown under stress [12]. In the same way, ozone stress induced two different responses in Petroselinum crispum [13], suggesting that different types of stress and their different intensities may lead to different responses in the plant quality.

Microwaves are radio waves with wavelengths ranging from one millimeter to one meter, or equivalently with frequencies between 0.3 and $300 \mathrm{GHz}$. Microwaves are used in spacecraft communication, and a lot of the world's data, and telephone communications are transmitted between long distances by microwaves between ground stations and communications satellites. Microwaves are also employed in microwave ovens and in radar technology.

Nowadays, the use of mobile telephony and wire-less devices has become more demanding hence generating an exponentially increased level of electromagnetic radiations. Intense microwave radiation can also affect the growth rate of plants and if the irradiated seeds germinate or not. Thus, it is important to know how the bioactive compounds from plants are affected.

Several microwave parameters were varied during the irradiation of wheat, bengal gram, green gram and moth bean seeds to study their influence on germination and growth rate [14]. It was observed that seed germination, seedling vigour, plant height, root length and biomass \% decrease with microwave power and exposure time.

Radish seeds exposed to $9.3 \mathrm{GHz}$ microwaves have found to be significantly increased the germination energy and germination in 8 year-old carrot seeds. Also, microwaves had positive effect on the amount of chlorophyll a, chlorophyll b, chlorophylls $\mathrm{a}+\mathrm{b}$ and carotenoids in tomato seedlings fresh mass, and negative effect in carrot seedlings fresh mass [15].

Khalafallah and Sallam [16] study the effect of microwave radiation at $945 \mathrm{MHz}$ on the growth rate and absorbance efficiency of photosynthetic pigments of Zea mays L. seedlings sown in the vicinity to install microwave base station near the agriculture fields. 
When wheat grains were exposed to microwave radiation of a wavelength $2.85 \mathrm{~cm}$ and frequency $10.525 \mathrm{GHz}$ for 15,45 , or $75 \mathrm{~min}$ an increase of protein and amino acid contents were observed. The contents of saccharides, nucleic acids, and phenolic compounds decreased. Also, low dose (15 min) stimulated proline synthesis, whereas the other doses showed negative effect on its production [17].

The effect of the low power microwave radiations on the concentration of phenolic compounds from Satureja hortensis L. and Ocimum basilicum L. was investigated. The results showed that the concentration of phenolic compounds is higher in irradiated plants compared to the non-irradiated plants $[18,19]$. In the literature there are few articles published on the effect of microwaves on the bioactive compounds from plants. Therefore, this study aims to investigate the effects of irradiation with microwave field on polyphenolic compounds from basil, celery and parsley. The results obtained from the irradiated plant were compared with the results obtained from the controlled plant (non-irradiated plants).

\section{MATERIAL AND METHODS}

\section{Chemical and reagents}

The rutin, caffeic acid and rosmarinic analytical standards were purchased from Sigma-Aldrich (Germany). Standards solutions were prepared by successive dilutions from $1 \mathrm{mg} / \mathrm{mL}$. Ethanol used for polyphenolic compounds extraction was purchased from Chimopar, Romania. Acetonitrile and methanol of HPLC grade were obtained from Merck, Germany. All chemicals were analytical grade.

\section{Plant material and growth condition}

The plants taken into study were grown in the laboratory, from seeds (ARO Company). At three weeks after seeding, vessels with sprung plants were placed in two identical anechoic chambers [20], one being the reference chamber and the other with the active microwave field. In the first chamber we placed the reference samples and in the second chamber we place the plants for irradiating, with microwaves at a frequency of $2.45 \mathrm{GHz}$ and the power of $14 \mathrm{dBm}$, radiation coming from a wireless router via a specially designed antenna. Irradiation was performed over a period of two weeks, each time, after which the plants were removed from the chamber, manually excised and used for polyphenols extraction and HPLC-MS analysis.

\section{Extraction of polyphenols}

For the characterization of non-irradiated and microwave irradiated plants the polyphenolic compounds were extracted with the extraction method previously established [10]. For this purpose $0.5 \mathrm{~g}$ plant were extracted in $40 \mathrm{~mL}$ ethanol - water (60: 40 , vol/vol) by sonication for 30 minutes in an Elmasonic S ultrasonic bath. After extraction the samples were filtered and the extracts were evaporated to dryness using a rotary evaporator at a temperature of less than $70{ }^{\circ} \mathrm{C}$. The residue was taken up in $10 \mathrm{~mL}$ extraction solvent. Each extraction was performed in three parallel samples.

\section{HPLC instrumentation and conditions}

The chromatographic analysis was carried out with a Shimadzu LC-MS 2010 system consisting of a binary pump, degasser, autosampler, thermostat set at $30^{\circ} \mathrm{C}$, PDA and MS detectors. Separation was carried out on a RP-18 column with a mobile phase of acetonitrile and water (1\% formic acid). Elution begins with a linear gradient starting with acetonitrile from $5 \%$ to $42 \%$ acetonitrile in 5 minutes, followed by elution with a 
linear gradient of acetonitrile up to $35 \%$ in 25 minutes. Mobile phase flow rate was 0.43 $\mathrm{mL} / \mathrm{min}$ and injection volume $10 \mu \mathrm{L}$. The plant extracts were decanted and filtered through nylon syringe filters $(0.45 \mu \mathrm{m})$ before HPLC-MS analysis. The peaks corresponding to the studied compounds showed maximum absorption at $354 \mathrm{~nm}$ for rutin, $324 \mathrm{~nm}$ for caffeic acid and $330 \mathrm{~nm}$ for rosmarinic acid.

\section{RESULTS AND DISCUSSIONS}

The aim of this study is to emphasize the influence of the low-power microwave field derived from a wireless device on polyphenolic compounds from some aromatic plants: basil, parsley and celery.

The growing conditions were almost identical in both chambers, the temperature and humidity in both chambers being permanently registered and showing a good correlation.

Qualitative analysis of polyphenolic compounds was achieved by high performance liquid chromatography coupled with the two analysis methods: UV spectroscopy and mass spectrometry.

Following the qualitative analysis of irradiated and non-irradiated extracts, the retention times, mass spectra and maximum wavelength of standard substances were compared with compounds from extracts. The following compounds were identified: routine in celery and parsley extracts, and caffeic acid and rosmarinic acid in basil extracts (Figure 1). The $330 \mathrm{~nm}$ detection wavelength gave the best abundance for the identified compounds. Also, it was observed that the irradiated and non-irradiated extract not vary from the qualitative point of view. The maximum wavelength and $\mathrm{m} / \mathrm{z}$ specific for the identified compounds are presented in Table 1.

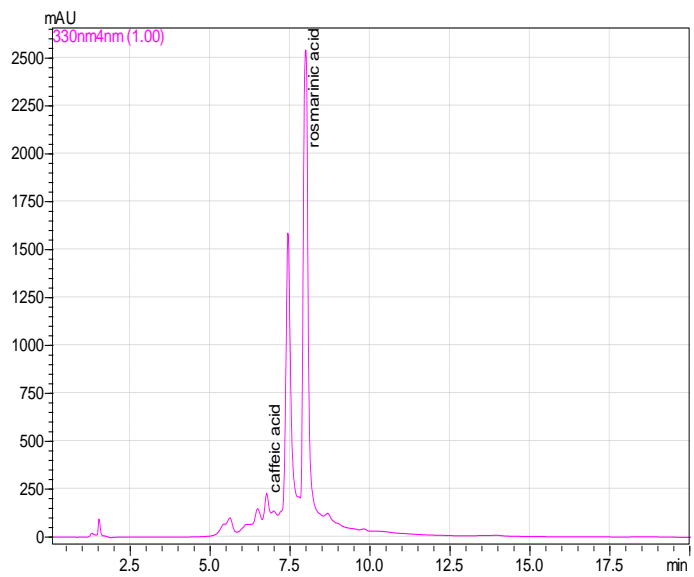

a)

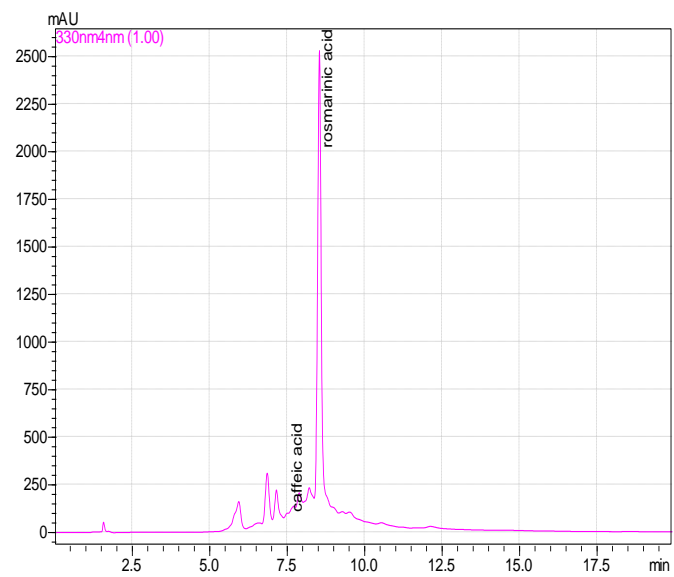

b)

Figure 1. Chromatograms of Ocimum basilicum L. extracts: non-irradiated (a); irradiated (b); obtained by ultrasound with a mixture $\mathrm{EtOH}-\mathrm{H}_{2} \mathrm{O}(60: 40$, vol/vol $)$

Table 1. Polyphenolic compounds identified in the studied plants

\begin{tabular}{ccccc}
\hline Compound & $t_{R}[\mathrm{~min}]$ & Maximum wavelength [nm] & RSD [\%] & $\mathrm{M}-\mathrm{H}^{+}$ \\
\hline Caffeic acid & 7.16 & 324 & 0.18 & 179 \\
Rosmarinic acid & 8.33 & 330 & 0.50 & 359 \\
Rutin & 7.55 & 253 & 0.36 & 609 \\
\hline
\end{tabular}

The best abundance for the identified compounds was obtained at three different wavelengths (Table 1). 
The HPLC conditions used at polyphenolic compounds separation ensured reproducible retention time and peak areas for investigated compounds.

Quantitative analysis of the polyphenolic compounds identified from basil extracts was carried out by external standard method. Standard solutions were prepared by dissolving the standards in methanol. Calibration curves for the standards were plotted using peak area versus concentration and are shown in Table 2.

Table 2. Parameters of linear regression for polyphenolic compounds identified in plants

\begin{tabular}{cccccc}
\hline Compound & $\begin{array}{c}\text { Range } \\
{[\mu \mathrm{g} / \mathrm{mL}]}\end{array}$ & $\begin{array}{c}\text { Linear regression } \\
\text { equation }{ }^{\mathrm{a}} \mathrm{y}=\mathrm{ax}+\mathrm{b}\end{array}$ & $\begin{array}{c}\text { Correlation } \\
\text { coefficient }\end{array}$ & $\begin{array}{c}\mathrm{LOQ} \\
{[\mu \mathrm{g} / \mathrm{mL}]}\end{array}$ & $\begin{array}{c}\mathrm{LOD} \\
{[\mu \mathrm{g} / \mathrm{mL}]}\end{array}$ \\
\hline $\begin{array}{c}\text { Caffeic acid } \\
\text { Rosmarinic }\end{array}$ & $0.05-10$ & $\mathrm{y}=110181 \mathrm{x}+12398$ & 0.9987 & 0.35 & 0.02 \\
$\begin{array}{c}\text { acid } \\
\text { Rutin }\end{array}$ & $0.1-10$ & $\mathrm{y}=50202 \mathrm{x}-2219$ & 0.9995 & 0.30 & 0.17 \\
\hline $\mathrm{a}=$ area, $\mathrm{x}=$ concentration $[\mu \mathrm{g} / \mathrm{mL}]$ & $\mathrm{y}=13473 \mathrm{x}+2237$ & 0.999 & 0.28 & 0.14 \\
\hline
\end{tabular}

The minimum concentration levels at which the compounds can be reliably detected (LOD) and quantified (LOQ) were found to be between $0.28-0.35 \mu \mathrm{g} / \mathrm{mL}$ and $0.02-0.17$ $\mu \mathrm{g} / \mathrm{mL}$.

To establish the precision of the HPLC proposed method, the repeatability (intra-day precision) were performed. For the determination of the validation parameters control plant extract were analyzed in one day. The determinations were performed on five analysis and the Relative Standard Deviations (RSD, \%) were calculated. The good repeatability of the proposed HPLC method was obtained as shown in Table 3.

Table 3. Repeatability of determination of polyphenolic compounds in control plant extract

\begin{tabular}{|c|c|c|c|c|c|c|c|}
\hline \multirow{2}{*}{ Content $[\mu \mathrm{g} / \mathrm{mL}]$} & \multicolumn{5}{|c|}{ No. of measurement } & \multirow[b]{2}{*}{ Mean } & \multirow{2}{*}{$\begin{array}{c}\text { RSD } \\
{[\%]}\end{array}$} \\
\hline & 1 & 2 & 3 & 4 & 5 & & \\
\hline Caffeic acid & 1.19 & 1.22 & 1.15 & 1.21 & 1.19 & 0.19 & 0.82 \\
\hline Rosmarinic acid & 347.51 & 341.38 & 337.06 & 345.99 & 344.03 & 343.19 & 0.48 \\
\hline Rutin & 0.83 & 0.86 & 0.88 & 0.84 & 0.82 & 0.85 & 1.09 \\
\hline
\end{tabular}

The identified compounds were quantified at maximum wavelength. The rutin, caffeic and rosmarinic acids content from the irradiated and control plants were compared (see Figures 2 and 3).

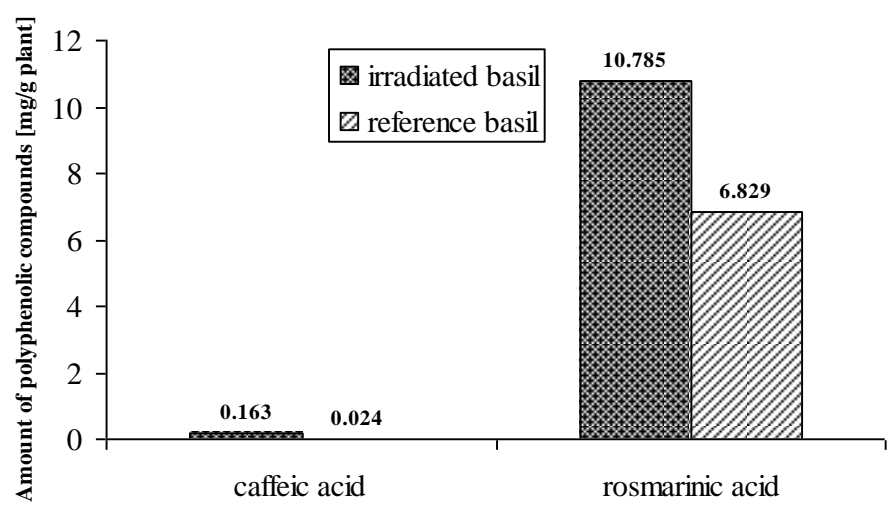

Figure 2. Comparison chart quantity of polyphenolic compounds from basil 


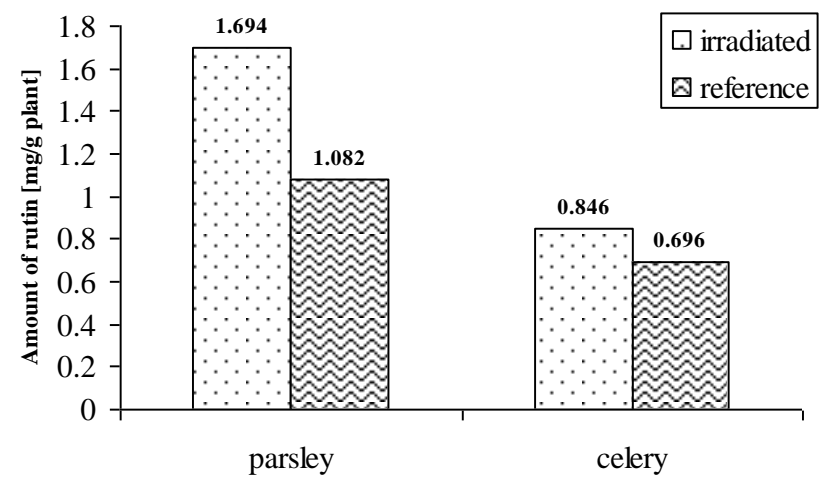

Figure 3. Comparison chart quantity of rutin from parsley and celery

The amount of polyphenolic compounds is greater in the plants subjected to microwave irradiation than in the reference plants. Thus, in the irradiated plant the quantity of caffeic acid, respectively rosmarinic acid is $101.23 \%$ and $57.93 \%$ higher compared to the reference basil plant. In the case of parsley and celery, the amount of rutin from irradiated plants is $56.56 \%$, respectively $21.55 \%$ higher than from the reference plants. Following the analysis it was observed that microwaves from a router wireless have a greater influence on caffeic acid.

Following the analysis it was observed that microwaves from a router wireless have a greater influence on caffeic acid compared to reference.

\section{CONCLUSION}

Experiments were carried out to study the effect of microwaves on polyphenolic compounds content of basil, parsley and celery plants irradiated during two weeks. It can be seen that the composition of irradiated and reference extracts not vary in terms of quality. The quantity of polyphenol compounds identified by HPLC (rutin, caffeic acid and rosmarinic acid) from irradiated extracts was found to be greater than that from the reference plants.

\section{ACKNOWLEDGMENTS}

The authors would like to express appreciation for the support of the Romanian National Authority for Scientific Research, CNCS - UEFISCDI, project number PN-II-RU-TE-2011-3-0283.

\section{REFERENCES}

1. Jiofack, T., Fokunang, C., Gudje, N., Kemeuze, V., Fongnzossie, E., Nkongmeneck, B. A., Mapongmetsem, P. M. and Tsabang, N., Ethnobotanical uses of Some Plants of Two Ethnoecological Regions of Cameroon, Afr. J. Pharm. Pharmacol., Vol. 2, No. 3, pp 664-684, 2009.

2. Balasundram, N., Sundram, K. and Samman, S., Phenolic Compounds in Plants and Agri-industrial By-products: Antioxidant Activity, Occurrence, and Potential Uses, Food Chem., Vol. 99, No. 1, pp 191-203, 2006, http://dx.doi.org/10.1016/j.foodchem.2005.07.042

3. Lee, J. and Scagel, C. F., Chicoric Acid Found in Basil (Ocimum basilicum L.) Leaves, Food Chem., Vol. 115, No. 2, pp 650-656, 2009, http://dx.doi.org/10.1016/j.foodchem.2008.12.075

4. Wong, P. Y. Y. and Kitts, D. D., Studies on the Dual Antioxidant and Antibacterial Properties of Parsley (Petroselinum crispum) and Cilantro (Coriandrum sativum) 
Extracts, Food Chem., Vol. 97, No. 3, pp 505-515, 2006, http://dx.doi.org/10.1016/j.foodchem.2005.05.031

5. Campanella, L., Bonnani, A., Favero, G. and Tomassetti, M., Determination of Antioxidant Properties of Aromatic Herbs, Olives and Fresh Fruit Using an Enzymatic Sensor, Anal. Bioanal. Chem., Vol. 375, No. 8, pp 1011-1016, 2003, http://dx.doi.org/10.1007/s00216-003-1825-1

6. Zhang, H., Chen, F., Wang, X. and Yao, H. Y., Evaluation of Antioxidant Activity of Parsley (Petroselinum crispum) Essential Oil and Identification of its Antioxidant Constituents, Food Res. Int., Vol. 39, No. 8, pp 833-839, 2006, http://dx.doi.org/10.1016/j.foodres.2006.03.007

7. Deng, C., Song, G., Zheng, X., Hu, Y. and Zhang, X., Analysis of the Volatile Constituents of Apium graveolens L. and Oenanthe L. by Gas Chromatography-mass Spectrometry, Using Headspace Solid-phase Microextraction, Chromatographia, Vol. 57, No. 11-12, pp 805-809, 2003, http://dx.doi.org/10.1007/BF02491769

8. Misic, D., Zizovic, I., Stamenic, M., Asanin, R., Ristic, M., Petrovic, S. D. and Skala, D., Antimicrobial Activity of Celery Fruit Isolates and SFE Process Modeling, Biochem. Eng. J., Vol. 42, No. 2, pp 148-152, 2008, http://dx.doi.org/10.1016/j.bej.2008.06.008

9. Oprică, L., Effect of Microwave on the Dynamics of Some Oxidoreductase Enzymes in Brassica Napus Germination Seeds, Annals of the "Alexandru Ioan Cuza" University Sect.II a.Genetics and Molecular Biology, Vol. 9, No. 3, pp 99-104, 2008.

10. Archana, R. and Namasivayam, A., Effect of Ocimum sanctum on Noise Induced Changes in Neutrophil Functions, J. Ethnopharmacol., Vol. 73, No. 1-2, pp 81-85, 2000, http://dx.doi.org/10.1016/S0378-8741(00)00281-6

11. Petropoulos, S. A., Daferera, D., Polissiou, M. G. and Passam, H. C., The Effect of Water Deficit Stress on the Growth, Yield and Composition of Essential Oils of Parsley, Sci. Hortic., Vol. 115, No. 4, pp 393-397, 2008, http://dx.doi.org/10.1016/j.scienta.2007.10.008

12. Ghassemi-Golezani, K., Zehtab-Salmasi, S. and Dastborhan, S., Changes in Essential Oil Content of Dill (Anethum graveolens) Organs Under Salinity Stress, J. Med. Plants Res., Vol. 5, No. 4, pp 3142-3145, 2011.

13. Eckeykaltenbach, H., Ernst, D., Heller, W. and Sandermann, H., Biochemical Plant Responses to Ozone (IV. Cross-Induction of Defensive Pathways in Parsley (Petroselinum crispum L.) Plants, Plant Physiol., Vol. 104, No. 1, pp 67-74, 1994.

14. Ragha, L., Mishra, S., Ramachandran, V. and Bhatia, M. S., Effects of Low-Power Microwave Fields on Seed Germination and Growth Rate, J. Electromagn. Anal. Appli., Vol. 3, No. 5, pp 165-171, 2011, http://dx.doi.org/10.4236/jemaa.2011.35027

15. Radzevičius, A., Sakalauskienè, S., Dagys, M., Simniškis, R., Karklelienè, R., Bobinas, C. and Duchovskis, P., The Effect of Strong Microwave Electric Field Radiation on: (1) Vegetable Seed Germination and Seedling Growth Rate, Zemdirbyste-Agriculture, Vol. 100, No. 2, pp 179-184, 2013, http://dx.doi.org/10.13080/z-a.2013.100.023

16. Khalafallah, A. A. and Sallam, S. M., Response of Maize Seedlings to Microwaves at 945 MHz, Romanian J. Biophys., Vol. 19, No. 1, pp 49-62, 2009.

17. Hamada, E. A. M., Effects of Microwave Treatment on Growth, Photosynthetic Pigments and Some Metabolites of Wheat, Biologia Plantarum, Vol. 51, No. 2, pp 343-345, 2007, http://dx.doi.org/10.1007/s10535-007-0068-y

18. Lung, I., Soran, M. L., Tudoran, C. and Măruţoiu, C., Effect of Microwave Irradiation on Polyphenolic Compounds from Satureja hortensis L., Cent. Eur. J. Chem., Vol. 11, No. 4, pp 535-541, 2013, http://dx.doi.org/10.2478/s11532-012-0188-x 
19. Lung, I., Soran, M. L., Stan, M. and Podar, D., Quantification of Total Flavonoids and Phenolic Acids from Microwave Irradiated and Non-irradiated Plants, Advances in Research, Vol. 1, No. 1, pp 1-10, 2013, http://dx.doi.org/10.9734/AIR/2013/6143

20. Surducan, E., Surducan, V. and Halmagyi, A., Romanian Patent, RO 125068/28.02.2012. 